IJBPAS, March, 2022, 11(3): 1081-1097

ISSN: $2277-4998$

International Journal of Biology, Pharmacy

and Allied Sciences (IJBPAS)

'A B Bridge Betusen caboratory and QRendo'

WwW.ijbpas.com

\title{
THERAPEUTIC POTENTIAL OF VARIOUS PHYTOCHEMICALS IN THE MANAGEMENT OF ALZHEIMER'S DISEASE
}

\author{
KUMAR M, KUMAR R, KHURANA N, SINGH SK AND KUMAR R * \\ Affiliation: School of Pharmaceutical Sciences, Lovely Professional University, Phagwara, \\ Punjab, India, 144411
}

*Corresponding Author: Dr. Rajan Kumar: E Mail: rajankumar2788@gmail.com; rajan.26188@Ipu.co.in

Received 13 ${ }^{\text {th }}$ April 2021; Revised $17^{\text {th }}$ May 2021; Accepted $14^{\text {th }}$ June 2021; Available online $1^{\text {st }}$ March 2022 https://doi.org/10.31032/IJBPAS/2022/11.3.5928

ABSTRACT

Alzheimer's disease (AD) is a chronic, progressive disease marked by memory loss and cognitive deficits. Various etiological factors are there which are responsible for the development of the Alzheimer's disease. Oxidative stress is one of the etiological factors which involved in the progression of the AD. It leads to the damage of the nerve fibres and accumulation of the beta amyloid in the nerve cells which further leads to decrease in the level of acetylcholine in the brain. Aggregation of beta amyloid in the nerve cells is the hall marks of AD. Acetylcholinesterase inhibitors, such as tacrine donepezil, galantamine, rivastigmine, and physiostigmine, can help to restore cholinergic activity, which has been linked to memory loss. Phytochemicals can play a major role in the management of AD. As, the most of the phytochemicals possess antioxidant activity and reduce the oxidative stress in the AD. This review focuses on the plant based active phytoconstituents that have been identified to be beneficial in the Alzheimer's disease during the pre-clinical studies.

Keywords: Alzheimer, oxidative stress, phytochemicals, beta-amyloid 


\section{INTRODUCTION}

Alzheimer's disease (AD) is a chronic, progressive disease marked by memory loss and cognitive deficits such as aphasia, agnosia, apraxia, and executive function. These deficiencies can cause problems in everyday life or at work. About 5.4 million Americans have been diagnosed with Alzheimer's disease [1, 2]. When people get older, their chances of developing Alzheimer's disease rise. This disease costs the US economy billions of dollars in direct health-care costs and lost opportunities each year, not to mention the enormous emotional toll it takes on patients and society. AD is estimated to have cost $\$ 604$ billion globally in 2010, a figure that is projected to rise as more people develop the disease (currently estimated at 36 million).Alzheimer's disease affects almost half of all Americans aged 85 and up. By 2050, it is expected that the number of people over the age of 80 will reach 370 million globally, with 50 percent of those over the age of 85 suffering from Alzheimer's disease [3, 4]. Multiple genetic and environmental factors play a role in this dementia, which is a complex neurodegenerative disease [5].

The pathophysiological pathways may have developed for years prior to diagnosis; given that cognitive dysfunction at the clinical onset of $\mathrm{AD}$ is a phenomenon that has progressed silently for several years. The causes of Alzheimer's disease are still being linked to complex interactions among multiple genetic, epigenetic, and environmental factors, according to pathophysiological data. The pathophysiology of Alzheimer's disease has been advanced by morphmetric measurements from post-mortem tissues to live patients using radiological imaging techniques [6]. Magnetic resonance imaging can detect gradual declines in cortical thickness that correlate with cognitive loss in Alzheimer's disease. In addition to the silencing of neurons, electrophysiological and biochemical evidence from transgenic mouse models indicate that $\mathrm{AD}$ could be linked to abnormal network behavior that actively interferes with biological processes underlying cognitive functions $[7,8]$. Loss of synapses and dendritic spines, rather than loss of neurons, is linked to cognitive impairment in Alzheimer's disease [9].

Theamyloid beta aggregation inhibitors, antioxidants, NGF mimics, PPAR agonists, calcium channel blockers, betaSecretase inhibitors, glycogen synthase kinase inhibitors, muscarinic receptor agonists, cholinesterase inhibitors, nicotinic 
receptor modulators, serotonin receptor antagonists, and non-steroidal antiinflammatory medications are among the treatments for Alzheimer. Various drug groups have been developed and accepted for the treatment of Alzheimer's disease based on these techniques. Acetylcholine esterase is inhibited by one of the medications currently approved by the FDA for the treatment of Alzheimer's disease. Cholinergic therapy is also one of the well developed treatments for mild to moderate Alzheimer's disease. Acetylcholinesterase inhibitors, such as tacrine donepezil, galantamine, rivastigmine, and physiostigmine, can help to restore cholinergic activity, which has been linked to memory loss [10].

AChE inhibitory activity has been found in a number of plants, suggesting that they may be useful in the treatment of neurodegenerative diseases like Alzheimer's disease. A lead has been found in identifying possible AChE inhibitors from plant sources, including those for memory disorders, using an ethnopharmacological approach and bioassay-guided isolation [11]. This review focuses on the plants based active constituents that have been identified to be beneficial in the Alzheimer's disease.

PHYTOCHEMICALS EXPLORED IN ALZHEIMER'S DISEASE

\section{Berberine}

Berberine is a natural isoquinoline alkaloid that is widely used as herbal medicine in China and is isolated from theChinese herb named Rhizomacoptidis. It came into awareness in recent years due to its numerous pharmacological and biochemical effects, as well as antibacterial, antiviral, and anticancer properties [12]. It has the ability to suppress the inflammatory events that occur in various inflammation-connected diseases [13] and is found to be effective against $\mathrm{AD}$, reported by various researchers.

Lin et al., 2020 reported the neuroprotective effect of berberine and its combination with curcumin. They observed that treatment with this combination enhances mice cognitive performance even more than the single-drug treatment, indicating that the use of berberine and curcumin together have synergistic effects. Furthermore, the mixture of Berberine and curcumin treatment reduced the soluble amyloid-peptide $(1-42)$ product. Furthermore, the combination therapy reduced inflammatory responses and oxidative stress in both the cortex and hippocampus of $\mathrm{AD}$ mice, demonstrating their anti-inflammatory and anti-oxidant effects. They also discovered that the combination therapy outperformed the single drugs in terms of lowering APP and BACE1 
levels while increasing AMPK phosphorylation and cell autophagy. The findings of this study, taken together, show the synergistic effects and possible underlying mechanisms of combined berberine and curcumin treatment in improving AD symptoms in mice. This study highlights a modern strategy for discovering new phytotherapy for Alzheimer's disease, as well as the importance of future studies focusing on the synergic effects of herbal medicines [14].

Panahi et al., 2013 reported the action of berberine on activity of $\beta$-secretase inhibitors in a rabbit Alzheimer's disease model. Untreated lesion (L), Control (C) and berberine chloride $(\mathrm{BC})$ treated + lesion $(\mathrm{L}+\mathrm{BC})$ groups of rabbits were used. Animals of $\mathrm{L}+\mathrm{BC}$ class received an oral dose of $50 \mathrm{mg} / \mathrm{kg}$ berberine chloride daily for 14 days after the surgery. Injection of water or vehicle including $25 \mathrm{mM}$ aluminum-maltol in $100 \mu \mathrm{l}$ concentration was induced to the lesion group through the intraventricular fissure. Paralysis, ataxia, tremor, and loss of weight were monitored and bieschowsky silver or H\&E staining was used for histopathology. The activity of $\beta$-secretase in the hippocampus was eventually measured. After 12-15 days of the lesion, all the animals of the L-group have died. In duration of 7-10 days after the lesion, uncharacteristic symptoms like cachexia were $90 \%$ of rabbits and L-group of rabbits lost their weight upto $500 \mathrm{~g}$ in between $10-12$ days $(\mathrm{p}<0.0522)$; not fully prevented from berberine chloride. On day 15 , every animal of group L died $(\mathrm{p}<$ $0.001)$. As we the berberine chloride treated animals, they all are protected from degeneration of the hippocampus, behavioral change and the BACE-1( $\beta$-site amyloid precursor protein cleaving enzyme-1) activity decreased [15]. Based on the results in terms ofhistological changes, physiological ability, and BACE-1 activity in the hippocampus, $\mathrm{BC}$ treatment may be a successful therapy for reversing $\mathrm{Al}$ maltol-induced behavioral alterations in the animal model of Alzheimer's disease.

\section{Caffeine}

Caffeine is a natural chemical stimulant and alkaloid that belongs to the methyl-xanthine family of compounds having the chemical formula $\mathrm{C}_{8} \mathrm{H}_{10} \mathrm{~N}_{4} \mathrm{O}_{2}$. Caffeine can protect from diseases by acting as antioxidant. Antioxidants are like defense mechanism of body which protect cells from oxidative damage. Antioxidants can help to decrease the oxidative reactions and also reduce tissue damage in body. Caffeic acid, chlorogenic acid, and melanoidins are the antioxidant types found in coffee which may be 
beneficial to many health issues which includes protection from heart disease and many cancer forms [16].

Arendash \& Cao, 2010 reported the effect of caffeine/coffee on cognitive impairment in the animal model of alzheimer's disease. The mice having Alzheimer's disease were used.From young adulthood to old age, caffeine is given to $\mathrm{AD}$ mice in their drinking water showed protection from memory loss and abnormal protein (amyloid-A $\beta: \beta$ ) in the lower brain levels which plays key role in the pathogenesis of Alzheimer's disease. After giving treatment of caffeine in 1-2 months, the impaired mice having $\mathrm{AD}$ restores their memory and $A \beta$ levels of lower brain [17].

\section{$>$ Curcumin}

Curcuminis major component present in the rhizome of curcuma species like curcuma longa (L). It belong to the family of zingiberaceae. It is made up of $77 \%$ curcumin and two other similar compounds, demethoxycurcumin and didemethoxycurcumin. These compounds are classified as diarylheptanoids but the combination of all 3 compounds are known as curcuminoid [18]. Curcumin has been shown in new medicine to have a broad range of pharmacological and biological properties including antioxidant, anti- inflammatory, chemoprotective, and neuroprotective properties, because of its ability to control a variety of signalling molecules [19].

Ray et al., 2011 reported the effect of cucumin's nanoparticle drug formulation on animal model of alzheimer's disease. A fully water soluble nanoparticle of curcumin (NanoCurc $^{\mathrm{TM}}$ ) was developed. Treatment with NanoCurc ${ }^{\mathrm{TM}}$ protects neuronally separated mammalian SK-N-SH cells from $\mathrm{H}_{2} \mathrm{O}_{2}$ oxidative damage.NanoCurc ${ }^{\mathrm{TM}}$ may also help separated mammalian SK-N-SH cells that have been damaged by $\mathrm{H}_{2} \mathrm{O}_{2}$. In vivo, Athymic mice is injected with 25 $\mathrm{mg} / \mathrm{kg}$ of NanoCurc ${ }^{\mathrm{TM}}$ injection two times daily. In the brains of NanoCurc ${ }^{\mathrm{TM}}$-treated athymic mice, biochemical analysis showed lower levels of $\mathrm{H}_{2} \mathrm{O}_{2}$, caspase $(3,7)$ level also decreases, and increase in the concentration if glutathione (GSH). These findings indicate that $\mathrm{NanoCurc}^{\mathrm{TM}}$ is an optimised formulation capable of evaluating the therapeutic benefit of curcumin in Alzheimer's disease [20].

Zhang et al., 2015 reported the effect of curcumin's ventricular injection on $\beta$ amaloid activity and working memory in animal model of alzheimr's disease. Zhang and his team investigated spatial and working memory of rats representing alzheimer's 
disease rodent model. The rats were receiving a amyloid- $\beta 1$ ventricular injection. The rats given Amyloid- $\beta 1$ showed cognitive deficits in the behavior. These rats were treated with curcumin $100 \mathrm{mg} / \mathrm{kg}$ daily. After seven days of treatment, there was improment in cognitive behavior of rats plus curcumin effect also increases BDNF and phosphorylated ERK levels of hippocampus. These results indicate that curcumin improves cognitive deficits associated with Alzheimer's disease which may be due to unregulation of BDNF-ERK hippocampus signaling developed by curcumin [21].

\section{$>$ Galantamine}

Galantamine is a tertiary alkaloid found in flowers and bulbs of Galanthussp and Leucojum aestivum L. It is an acetylcholinesterase (AChE) inhibitor used for alzheimer's disease treatment. Galantamine has been discovered to be an allosteric modulator of the nicotinic acetylcholine receptor (nAChR). nAChR stimulation raises intracellular calcium levels and enhances noradrenaline release which both enhances the cognitive levels of brain [22].

Van Dam \& De Deyn, 2006 reported the combination effect of memantine and galantamine on APP23 mutated animal model of Alzheimer disease. The APP23 mice models were used and treated with saline, memantine $(7.2 \mathrm{mg} / \mathrm{kg})$ and galntamine $(1.3 \mathrm{mg} / \mathrm{kg})$ daily through subcutanic osmotic pumps for two months. For prevention of bias, the rats were set for wash out time of three weeks to avoid systematic effects. The morris water test was taken, it was observed that the spatial accuracy of probe trial is enhanced by small dose of galantamine as well as memantine significantly increase the spatial memory and acquisition performance of probe trial. This was the first research which showed that memantine and galantamine will slow the progression of Alzheimer's disease in transgenic mice [23].

$\mathrm{Su}$ et al., 2014 reported the neuroprotective action of gallantamine (anticholinestrase inhibitor) on spatial and working memory induced by MK-801 in the animal model of alzheimer disease. Male rats of sprague-dawley were used and treated in paroxysmal nocturnal dyspnea (PND) with MK-801 (0.25 mg/kg) or salinedaily and long-term behaviour of rats were being recorded. Treatment with MK- 801 displayed mild working memory impairments in puberty age of rats, but a significant deficit in the age of adult rats.However, this treatment had no effect onprepulse inhibition orlocomotion in two life stages. Signifantly 
now rats were treated with galantamine $(1 \mathrm{mg} / \mathrm{kg})$ before 30 minutes of every session of training resulted in spatial and working memory improvement induced by MK-801 in adult rats. This results suggested that galantamine treatment was benificial for all infected animals of MK-801 [24].

\section{Nicotine}

Nicotine is a natural alkaloid found in the plant of tobacco having chemical formula of $\mathrm{C}_{10} \mathrm{H}_{14} \mathrm{~N}_{2}$. It belongs to family of Solanaceae. It is CNS (central nervous system) stimulant which stimulates the ganglion in lower dose and block the ganglion in higher dose. Nicotine binds to nicotinic cholinergic receptors in the neuromuscular junctions, autonomic ganglia, the adrenal medulla, and the cortex, and behaves as an agonist.

Martí Barros et al., 2004 reported the effect of nicotine on nicotinic recptors of hippocampus in rats. Chronic cannulae was inserted in the first region of hippocampus of rats. Foot shock of $0.5 \mathrm{~mA}$ was given to rats and measured the STM twice in each gap of 90 minutes as well as LTM is measured after a day. Then rats were treated with nACHR (nicotinic receptors) antagonists of dihydro$\beta$-erythroidine $(18,6$ and $2 \mu \mathrm{g} /$ side $)$ and mecamylamine $(10,3$ and $1 \mu \mathrm{g} /$ side $)$ as well as the nACHR agonist of nicotine $(3,1$ and
$0.6 \mu \mathrm{g} / \mathrm{side})$. Before and after $15 \mathrm{~min}$ of training, drugs are given and also given 15 min earlier of LTM testing. The results shows that treatment of nicotine enhances the STM and LTM respectively, where DH $\beta E$ and mecamylamine failed [25].

Socci et al., 1995 reported the nicotine effect on retention and acquisition of the morris water maze on young rats of 2 or 3 months and aged rats of 2 years. Rats were given treatment of nicotine or saline water $(0.2 \mathrm{mg} / \mathrm{kg})$ before the three days of testing and before 15 minutes of regular testing. Vehicle-treated young rats performed good in water maze acquisition as compared to aged rats. Nicotine improved the acquisition of aged rats significantly. Nicotine also helped young rats remember things better. The findings indicate that nicotine and its agonists may be helpful in the treatment ofor age-related memory loss orAlzheimer's disease [26].

\section{Physostigmine}

Physostigmine is a African alkaloid derived from physostigma venonosum balf seed. It is AChE (antichilinestrase) inhibitor [27] used for the treatment of glaucoma, atropineinduced coma and intoxification of many tricyclic antidepressants or anti-cholinergics like atropine, imipramine, scopolamine etc. [28]. Physostigmine is used as potent 
antidote for anticholinergic toxicity. It has property to cross the blood bain barrier rapidly and it is centrally acting carbamate. It has fewer side effects than other AChE inhibitors, so it is benifial for the treatment of Alzheimer disease [29].

Dong et al., 2005 reported the effects of acetylcholinestrase inhibitory drugs on memory-related activities and formation of $\beta$ Amaloid plaque in the animal model of alzheimer's disease. Transgenic Tg2576 mice were used and devided into two groups Tgpositive and Tg-negative according to genotype. Each group of $\mathrm{Tg}$-positive and Tg-negative contain 16 mice and they again were differentiated into 3 classes (5-6 mice in each class of Tg-positive and Tg-negative mice). Over the course of six weeks, the animals in the first two classes were given increasing dosage of donepezil $(0.1,0.3$ and $1 \mathrm{mg} / \mathrm{kg})$ or physostigmine $(0.03,0.1$ and $0.3 \mathrm{mg} / \mathrm{kg}$ ) and the remaining class received saline injection regularly. Fear condition and learning memory was examined after every dose during the course of drug administration. The animals were killed after the drug administration was finished, and the plaque number was calculated.Donepezil and Physostigmine strengthened Tg-positive mice's spatial and cued memory deficits, allowing them to behave more like Tg- negative mice.Physostigmine was found to have a stronger impact on enhancing contextual memory, and donepezil was found to be more effective in enhancing deficits in spatial memory acquisition.Neither medication affected the formation of $\beta$ Amaloid plaques [30].

Aigner \& Mishkin, 1986 reported the combination effect of scopolamine and physostigmine on remembering memory of monkeys. The DNMS (delayed non-matching to sample) test was used to find the optical recognition of rhesus monkeys using different objects. Every regular sessions consisted of twenty objects each in two groups that untreated animals could identify with about $75 \%$ accuracy. The monkeys were doing normal at this level. After this level the monkeys were treated with drugs of scopolamin, physostigmine and saline before twenty minutes of session.The drugs were given to the monkeys in increasing or decreasing dose respectively. In the result, the treatment with scopolamine and physostigmine enhanced the remembering memory of monkeys as they were recognising the objects more correctly the before treatment [31].

\section{Resveratrol}

Resveratrol (3,5,4'-tryhydroxy-trans-stilbene) is a natural polyphenolic compond belonging 
to the family of phytoalexin [32]. It was isolated from traditional medicine of china and japan named polygonum cuspidatum [33]. Is is also present in seeds and skins of many other species of plants (more than 70 species of plants) which includes, berries, grapes, panuts, and tea [34]. Clinically, resveratrol is also very useful which includes protection from imflamation or oxidative streass and development of cancer, diabetes, and many neurodegerative diseases like parkinson's disease, alzheimer's disease, or cerbral ischemia [35-37].

Y.-T. Lin et al., 2018 reported the effect of resveratrol in reducing the reactive oxygen species (ROS) and congitive impairment in the rat model of alzheimer's disease. Wistar kyoto male rats having $\mathrm{AD}$ induced by angiotensin-II were used in this experiment. The infected rats were treated with resveratrol $(10 \mathrm{mg} / \mathrm{kg})$ and losartan $(10$ $\mathrm{mg} / \mathrm{kg}$ ) daily for 14 days resulted, increase in BDNF (brain derived neurotropic factor) of hippocampus, BP (blood pressure) decreased, production of ROS decreased. Losartan also inhibits Tau phosphorylation in the hippocampal nucleus activated Akt phosphorylation and eliminates the $\beta$ amaloid precursors induced by angiotensin II. When compared to losartan, resveratrol consistently had the same effects. Both resveratrol and losartan enhanced the contexual memory of rats by elevation of dismutase-2 superoxide and deletion of NOX-2 (NADPH oxidase2). According to the results, both drugs showed neuroprotective effects in recovering memory and reduction of oxidative damage of hippocampus in the rat model of alzheimer's disease [38].

Huang et al., 2011 reported theneuropretective effect of resveratrol on neuronal toxicity induced by $\beta$-amaloid precursor and recovering memory loss in the rat model of alzheimer's disease. Young rats of sprague-dawley were used and they were injected with $\beta$-amaloid precursor. resulted in the spatial memory impairment, iNOS (induced nitric oxide sythase) level increased, peroxidation of lipids, and $\mathrm{HO}^{-1}$ (heme oxygenase) expressiom decreased. Then rats were treated with resveratrol resulted in spacial memory enhancment, and protection against $\beta$-amaloid induced neuronal toxicity. Resveratrol's neuroprotective effects were attributed to decrease in cellular iNOS and lipid peroxidation, as well as an increase in HO-1 production [39].

\section{Quercetin}

Quercetin

$\left(3,3^{\prime}, 4^{\prime}, 5,7-\right.$ pentahydroxyflavanone) is the predominant 
flavanoid founded in many vegetables and fruits. Human diet contains 3-38 $\mathrm{mg}$ of quercetin which we intake daily [40]. Berries, cherries, apples, asparagus, onions, and red leaf letture are the rich source of Quercetin [41]. The name "quercetin" is derived from the Latin word "quercetum," which refers to a yellow-colored substance that dissolves in lipids and alcohol, moderately soluble in hot water, and insoluble in cold water [42]. Quercetin as flavanoid is also used for the treatment of memory impairment diseases like, oxidative stress, isxhemia, hypoxia, seizure, and Alzheimer's disease [43-44].

Khan et al., 2018 reported the neuroprotective properties of quercetin on lipopolysaccharide dentrimental effects in the brain of mouse model. An adult mice were used and treated with I.P.(intra-peritonial) injection of lipopolysaccharides $(0.25 \mathrm{mg} / \mathrm{kg})$ daily for 7 days resulted in, cytokines secreation due to glial activation, degeration of neurons, and activation of apoptotic pathway of mitochondria. When compared to Lipopolysaccharide treatment, the treatment of quercetin $(30 \mathrm{mg} / \mathrm{kg})$ I.P. injection daily for 2 weeks (1 week before lipopolysaccharides treatment and 1 week with lipopolysaccharides treatment) resulted in, reduction of cytokines secreations and different imflamatory activities, and prevention against neuronal imflamation caused in hippocampus and cortex of adult mice. Quercetin also stopped the apoptotic pathway of mitochondria and degeration of neurons by controlling $\mathrm{Bax} / \mathrm{Bcl} 2$, lowering the activity of caspase- 3 and cytochrome-c in the hippocampal and cortical parts of the mice brains. The results showed that quercetin treatment decreased the synaptic loss of neurons induced by lipopolysaccharide and also improved the memory power of lipopolysaccharide treated mice [45].

Sabogal-Guáqueta et al., 2015 reported the neuroprotective properties of quercetin in the treatment of triple transgenicalzheimer's disease (3xTg-AD) mice model. The adult 3xTg-AD mice were used and treated with I.P. (Intra-peritonial) injection of quercentin (25 $\mathrm{mg} / \mathrm{kg})$ after every two days for 3 months at the age of 21 months old. The result showed that reduction of tau-phosphorylation, $\beta$-amaloids, and glial activation in the hippocampal region of mice brain. Quercetin was also helpul in the reduction of PHF (paired helical filament), and different levels (1-40 and 1-42) of $\beta$ amaloids. In addition, the elevated maze tests showed that quercetin enhanced spatial and learning memory of mice. These findings 
showed that quercetin treatment is good for 3xTg-AD mice [46].

\section{$>$ Nobiletin}

Nobiletin (3',4',5,6,7,8-hexamethoxyflavone) is a flavanoid founded in the citrus peels. It is polymethoxyflavone having chemical formulaC $\mathrm{C}_{21} \mathrm{H}_{22} \mathrm{O}_{8}$ [47]. According to the recent researches, nobiletin is multifunctional pharmaceutical agent. It has high lipophilic and permeability profile [48]. It is used as a protection barrier for many diseases which include cardiovascular diseases, and neurodegerative diseases. It has also antiimflamation, anti-cancer, and anti-oxidation properties $[47,49,50]$.

Nakajima et al., 2015 reported effects of nobiletin on reduction of $\beta$-amaloids levels and cognititive ampairment improvement in3XTg-AD(triple transgenic Alzheimer's disease) animal model. The 3XTG-AD mice were used and treated with $30 \mathrm{mg} / \mathrm{kg}$ of nobiletin daily for three months. The treatment of nobiletin resulted in improvement of remembering memory and STM (short-term memory) of $3 \times T$ g-AD mice. The soluble $\beta$-amaloid levels of mice were also reduced by action of nobiletin, seen in ALISA analysis reports. Also, noliletin also decreases the oxygen's reactive species levels in tha brain of 3xTg-AD mice. These findings indicate that nobiletin, a natural synthesized drug may be developed into a novel medication for the treatment and prevention of Alzheimer's disease [51].

Qu et al., 2018 reported the actions of nobiletin in ROS (oxygen's reactive species) inhibition and modulation of akt/mTOR, and JNK/ERK pathways in experimental rodent model. Male rats of sprague dawley were used and they were separated into 10 rats each of five groups, one group (control group) was given diurnal saline injections and to the other (cadmium-treated) group cadmium chloride $(2 \mathrm{ml} / \mathrm{kg})$ with saline were given to the rats subcutaneously daily for 1 month resulted in $1 \mathrm{mg} / \mathrm{kg}$ cadmium dose range. Before some days of cadmium treatment, nobiletin $(200,100$, and $50 \mathrm{mg} / \mathrm{kg})$ was given to rats through oral route during period of studies. In the result, nobiletin inhibited the MDA (malondialdehyde) and ROS-levels induced by cadmium and also enhanced the gltuathione levels. It increases the capase-3 levels and decreased the neuronal (Cd-induced) apoptosis. Nobiletin stopped the down regulation and phosphorylation of JNK/Erk pathways. These neuroprotective effects shows that nobiletin is a good treatment of neurotoxicity induced by nobiletin [52].

\section{CONCLUSION}


The studies presented here show that phytochemicals not only have potent antioxidant and anti-inflammatory properties, acting to scavenge radicals and control inflammatory responses, but also that they can easily cross the blood-brain barrier to operate on particular targets implicated in the pathogenesis of Alzheimer's disease. Phytochemicals also improve cellular defense mechanisms by activating endogenous pro-survival pathways, which can protect the brain from plaque deposition and beta amyloid proteins. Neuroprotective phytochemicals extracted from fruits and vegetables are appealing alternatives to pharmaceuticals like NSAIDs and antidegenerative molecules, which have yet to be proven in clinical trials and are associated with major safety concerns. Phytochemicals have a lot of potential as effective, affordable, and readily available as antiAlzheimer agent.

\section{REFERENCES}

[1] R. Epis, F. Gardoni, E. Marcello, A. Genazzani, P.L. Canonico, M. Di Luca, Searching for new animal models of Alzheimer's disease, Eur. J. Pharmacol. 626 (2010) $57-63$. https://doi.org/10.1016/j.ejphar.2009.10. 020.

[2] 2021 Alzheimer's disease facts and figures, Alzheimer's Dement. 17 (2021)
327-406.

https://doi.org/10.1002/alz.12328.

[3] I. McDowell, Alzheimer's disease: Insights from epidemiology, Aging Clin. Exp. Res. 13 (2001) 143-162. https://doi.org/10.1007/bf03351474.

[4] Y.H. Suh, F. Checler, Amyloid precursor protein, presenilins, and $\alpha$-synuclein: Molecular pathogenesis and pharmacological applications in Alzheimer's disease, Pharmacol. Rev. 54 (2002) $469-525$. https://doi.org/10.1124/pr.54.3.469.

[5] M. Hüll, M. Berger, M. Heneka, Diseasemodifying therapies in Alzheimer's disease: How far have we come?, Drugs. $66 \quad$ (2006) 2075-2093. https://doi.org/10.2165/00003495200666160-00004.

[6] H. Hampel, R. Frank, K. Broich, S.J. Teipel, R.G. Katz, J. Hardy, K. Herholz, A.L.W. Bokde, F. Jessen, Y.C. Hoessler, W.R. Sanhai, H. Zetterberg, J. Woodcock, K. Blennow, Biomarkers for alzheimer's disease: Academic, industry and regulatory perspectives, Nat. Rev. Drug Discov. 9 (2010) 560-574. https://doi.org/10.1038/nrd3115.

[7] J.J. Palop, J. Chin, L. Mucke, A network dysfunction perspective on neurodegenerative diseases, Nature. 443 (2006)

768-773. https://doi.org/10.1038/nature05289.

[8] L. Verret, E.O. Mann, G.B. Hang, A.M.I. 
Barth, I. Cobos, K. Ho, N. Devidze, E. Masliah, A.C. Kreitzer, I. Mody, L. Mucke, J.J. Palop, Inhibitory interneuron deficit links altered network activity and cognitive dysfunction in alzheimer model, Cell. 149 (2012) 708-721. https://doi.org/10.1016/j.cell.2012.02.046

[9] J.J. Palop, L. Mucke, Amyloid-Binduced neuronal dysfunction in Alzheimer's disease: From synapses toward neural networks, Nat. Neurosci. 13 (2010) 812-818. https://doi.org/10.1038/nn.2583.

[10] E.D. Roberson, L. Mucke, 100 Years and counting: Prospects for defeating Alzheimer's disease, Science (80-. ). 314 (2006) 781-784. https://doi.org/10.1126/science.113281 3.

[11] P.K. Mukherjee, V. Kumar, M. Mal, P.J. Houghton, Acetylcholinesterase inhibitors from plants, Phytomedicine. 14 (2007) 289-300. https://doi.org/10.1016/j.phymed.2007. 02.002 .

[12] H.F. Ji, L. Shen, Berberine: A potential multipotent natural product to combat Alzheimer's disease, Molecules. 16 (2011) 6732-6740. https://doi.org/10.3390/molecules 16086 732.

[13] E.J. Seo, N. Fischer, T. Efferth, Phytochemicals as inhibitors of NF- $\kappa$ B for treatment of Alzheimer's disease, Pharmacol. Res. 129 (2018) 262-273. https://doi.org/10.1016/j.phrs.2017.11.0 30.

[14] L. Lin, C. Li, D. Zhang, M. Yuan, C. hai Chen, M. Li, Synergic Effects of Berberine and Curcumin on Improving Cognitive Function in an Alzheimer's Disease Mouse Model, Neurochem. Res. 45 (2020) 1130-1141. https://doi.org/10.1007/s1 1064-02002992-6.

[15] N. Panahi, M. Mahmoudian, P. Mortazavi, G.S. Hashjin, Effects of berberine on $\beta$-secretase activity in a rabbit model of Alzheimer's disease, Arch. Med. Sci. 9 (2013) 146-150. https://doi.org/10.5114/aoms.2013.3335 4.

[16] T. Wolde, Effects of caffeine on health and nutrition: A Review, 30 (2014) 5966.

[17] G.W. Arendash, C. Cao, Caffeine and Coffee as Therapeutics Against Alzheimer' s Disease, 20 (2010) 117126. https://doi.org/10.3233/JAD-2010091249.

[18] M.L.A.D. Lestari, G. Indrayanto, Curcumin, 2014. https://doi.org/10.1016/B978-0-12800173-8.00003-9.

[19] T.A.M.J. C, J. Prickaerts, C. Vingerhoets, The effect of curcumin on cognition in Alzheimer's disease and 
healthy aging: A systematic review of pre-clinical and clinical studies, Brain Res. $1725 \quad$ (2019) 146476. https://doi.org/10.1016/j.brainres.2019. 146476.

[20] B. Ray, S. Bisht, A. Maitra, A. Maitra, D.K. Lahiri, Neuroprotective and neurorescue effects of a novel polymeric nanoparticle formulation of curcumin (NanoCurc ${ }^{\mathrm{TM}}$ ) in the neuronal cell culture and animal model: Implications for Alzheimer's disease, J. Alzheimer's Dis. 23 (2011) 61-77. https://doi.org/10.3233/JAD-2010101374.

[21] L. Zhang, Y. Fang, Y. Xu, Y. Lian, N. Xie, T. Wu, H. Zhang, L. Sun, R. Zhang, Z. Wang, Curcumin improves amyloid $\beta$-peptide (1-42) induced spatial memory deficits through BDNFERK signaling pathway, PLoS One. 10 (2015) 1-17. https://doi.org/10.1371/journal.pone.01 31525.

[22] G. C, I. Philipova, A. Lukarski, M. Atanasova, Galantamine-Curcumin Hybrids as Dual-Site Binding Acetylcholinesterase Inhibitors, (2020) 1-18. https://doi.org/10.3390/molecules25153 341.

[23] D. Van Dam, P.P. De Deyn, Cognitive evaluation of disease-modifying efficacy of Galantamine and
Memantine in the APP23 model, Eur. Neuropsychopharmacol. 16 (2006) 5969.

https://doi.org/10.1016/j.euroneuro.200 5.06.005.

[24] Y.A. Su, R.H. Huang, X.D. Wang, J.T. Li, T.M. Si, Impaired working memory by repeated neonatal MK-801 treatment is ameliorated by galantamine in adult rats, Eur. J. Pharmacol. 725 (2014) 3239.

https://doi.org/10.1016/j.ejphar.2014.01 .007 .

[25] D. Martí Barros, M.R. Ramirez, E.A. Dos Reis, I. Izquierdo, Participation of hippocampal nicotinic receptors in acquisition, consolidation and retrieval of memory for one trial inhibitory avoidance in rats, Neuroscience. 126 (2004) 651-656. https://doi.org/10.1016/j.neuroscience.2 004.03.010.

[26] D.J. Socci, P.R. Sanberg, G.W. Arendash, Nicotine enhances morris water maze performance of young and aged rats, Neurobiol. Aging. 16 (1995) 857-860. https://doi.org/10.1016/01974580(95)00091-R.

[27] E.L. Konrath, C.D.S. Passos, L.C. Klein-Júnior, A.T. Henriques, Alkaloids as a source of potential anticholinesterase inhibitors for the treatment of Alzheimer's disease, J. Pharm. Pharmacol. 65 (2013) 1701- 
1725 .

https://doi.org/10.1111/jphp.12090.

[28] M.J. Burns, C.H. Linden, A. Graudins, R.M. Brown, K.E. Fletcher, A comparison of physostigmine and benzodiazepines for the treatment of anticholinergic poisoning, Ann. Emerg. Med. 35 (2000) 374-381. https://doi.org/10.1016/S01960644(00)70057-6.

[29] I. Vol, I. Oct, A. Singh, S.P. Srivastava, M. Asad, P. Pathak, S. Kumar, A review on physostigmine: As antidote and treatment of Alzhemier disease, 4 (2015) 512-517.

[30] H. Dong, C.A. Csernansky, M. V. Martin, A. Bertchume, D. Vallera, J.G. Csernansky, Acetylcholinesterase inhibitors ameliorate behavioral deficits in the $\operatorname{Tg} 2576$ mouse model of Alzheimer's disease, Psychopharmacology (Berl). 181 (2005) 145-152. https://doi.org/10.1007/s00213-0052230-6.

[31] T.G. Aigner, M. Mishkin, The effects of physostigmine and scopolamine on recognition memory in monkeys, Behav. Neural Biol. 45 (1986) 81-87. https://doi.org/10.1016/S01631047(86)80008-5.

[32] S.D. Rege, T. Geetha, G.D. Griffin, T.L. Broderick, J.R. Babu, Neuroprotective effects of resveratrol in
Alzheimer disease pathology, Front. Aging Neurosci. 6 (2014) 1-27. https://doi.org/10.3389/fnagi.2014.0021 8.

[33] S. Nonomura, H. Kanagawa, A. Makimoto, Chemical constituents of polygonaceous plants. i. studies on the, Yakugaku Zasshi. 83 (1963) 988-990. https://doi.org/10.1248/yakushi1947.83. 10_988.

[34] G.J. Soleas, E.P. Diamandis, D.M. Goldberg, Wine as a biological fluid: History, production, and role in disease prevention, J. Clin. Lab. Anal. 11 (1997)

287-313.

https://doi.org/10.1002/(SICI)1098-

2825(1997)11:5<287::AID-

JCLA6>3.0.CO;2-4.

[35] S. Das, D. Das, Anti-Inflammatory Responses of Resveratrol, Inflamm. Allergy-Drug Targets. 6 (2007) 168173.

https://doi.org/10.2174/1871528077816 96464.

[36] P.M. Kris-Etherton, K.D. Hecker, A. Bonanome, S.M. Coval, A.E. Binkoski, K.F. Hilpert, A.E. Griel, T.D. Etherton, Bioactive compounds in foods: Their role in the prevention of cardiovascular disease and cancer, in: Am. J. Med., Elsevier Inc., 2002: pp. 71-88. https://doi.org/10.1016/s0002-

9343(01)00995-0.

[37] J.A. Baur, D.A. Sinclair, Therapeutic 
potential of resveratrol: The in vivo evidence, Nat. Rev. Drug Discov. 5 (2006) 493-506. https://doi.org/10.1038/nrd2060.

[38] Y.-T. Lin, Y.-C. Wu, G.-C. Sun, C.-Y. Ho, T.-Y. Wong, C.-H. Lin, H.-H. Chen, T.-C. Yeh, C.-J. Li, C.-J. Tseng, P.-W. Cheng, Effect of Resveratrol on Reactive Oxygen Species-Induced Cognitive Impairment in Rats with Angiotensin II-Induced Early Alzheimer's Disease †, J. Clin. Med. 7 (2018) 329. https://doi.org/10.3390/jcm7100329.

[39] T. Huang, K. Lu, Y.P. Wo, Y. Wu, Y. Yang, Resveratrol Protects Rats from A b -induced Neurotoxicity by the Reduction of iNOS Expression and Lipid Peroxidation, 6 (2011). https://doi.org/10.1371/journal.pone.00 29102.

[40] C. Manach, G. Williamson, C. Morand, A. Scalbert, C. Rémésy, Bioavailability and bioefficacy of polyphenols in humans. I. Review of 97 bioavailability studies., Am. J. Clin. Nutr. 81 (2005). https://doi.org/10.1093/ajen/81.1.230s.

[41] L.G. Costa, J.M. Garrick, P.J. Roquè, C. Pellacani, Mechanisms of Neuroprotection by Quercetin: Counteracting Oxidative Stress and More, Oxid. Med. Cell. Longev. 2016 (2016).

https://doi.org/10.1155/2016/2986796.
[42] A.V. Anand David, R. Arulmoli, S. Parasuraman, Overviews of biological importance of quercetin: A bioactive flavonoid, Pharmacogn. Rev. 10 (2016) 84-89. https://doi.org/10.4103/09737847.194044 .

[43] T.T. Bui, T.H. Nguyen, Natural product for the treatment of Alzheimer's disease, J. Basic Clin. Physiol. Pharmacol. 28 (2017) 413-423. https://doi.org/10.1515/jbcpp-20160147.

[44] G.L. Viswanatha, L.M. Sharath Kumar, M. Rafiq, K.J. Kavya, A.H Thippeswamy, H. Chandrashekarappa Yuvaraj, M. Azeemuddin, S.D. Anturlikar, P.S. Patki, U.V. Babu, S. Ramakrishnan, LC-MS/MS profiling and neuroprotective effects of Mentat ${ }^{\circledR}$ against transient global ischemia and reperfusion-induced brain injury in rats, Nutrition. 31 (2015) 1008-1017. https://doi.org/10.1016/j.nut.2015.02.00 9.

[45] A. Khan, T. Ali, S.U. Rehman, M.S. Khan, S.I. Alam, M. Ikram, T. Muhammad, K. Saeed, H. Badshah, M.O. Kim, Neuroprotective Effect of Quercetin Against the Detrimental Effects of LPS in the Adult Mouse Brain, 9 (2018) 1-16. https://doi.org/10.3389/fphar.2018.0138 3.

[46] A.M. Sabogal-Guáqueta, J.I. Muñoz- 
Manco, J.R. Ramírez-Pineda, M. Lamprea-Rodriguez, E. Osorio, G.P. Cardona-Gómez, The flavonoid quercetin ameliorates Alzheimer's disease pathology and protects cognitive and emotional function in aged triple transgenic Alzheimer's disease model mice, Elsevier Ltd, 2015. https://doi.org/10.1016/j.neuropharm.20 15.01.027.

[47] H. Huang, L. Li, W. Shi, H. Liu, J. Yang, $\mathrm{X}$. Yuan, L. Wu, The Multifunctional Effects of Nobiletin and Its Metabolites in Vivo and in Vitro, Evidence-Based Complement. Altern. Med. $2016 \quad$ (2016). https://doi.org/10.1155/2016/2918796.

[48] S.P. Singh, Wahajuddin, D. Tewari, K. Patel, G.K. Jain, Permeability determination and pharmacokinetic study of nobiletin in rat plasma and brain by validated high-performance liquid chromatography method, Fitoterapia. 82 (2011) 1206-1214. https://doi.org/10.1016/j.fitote.2011.08. 010.

[49] E. Yoshigai, T. Machida, T. Okuyama, M. Mori, H. Murase, R. Yamanishi, T. Okumura, Y. Ikeya, H. Nishino, M. Nishizawa, Citrus nobiletin suppresses inducible nitric oxide synthase gene expression in interleukin-1 $\beta$-treated hepatocytes, Biochem. Biophys. Res. Commun. 439 (2013) 54-59. https://doi.org/10.1016/j.bbrc.2013.08.0 29.

[50] L. Zhang, X. Zhang, C. Zhang, X. Bai, J. Zhang, X. Zhao, L. Chen, L. Wang, C. Zhu, L. Cui, R. Chen, T. Zhao, Y. Zhao, Nobiletin promotes antioxidant and anti-inflammatory responses and elicits protection against ischemic stroke in vivo, Brain Res. 1636 (2016) 130-141.

https://doi.org/10.1016/j.brainres.2016.

02.013.

[51] A. Nakajima, Y. Aoyama, E.J. Shin, Y. Nam, H.C. Kim, T. Nagai, A. Yokosuka, Y. Mimaki, T. Yokoi, Y. Ohizumi, K. Yamada, Nobiletin, a citrus flavonoid, improves cognitive impairment and reduces soluble $\mathrm{A} \beta$ levels in a triple transgenic mouse model of Alzheimer's disease (3XTgAD), Behav. Brain Res. 289 (2015) 6977.

https://doi.org/10.1016/j.bbr.2015.04.02 8.

[52] Y. Qu, Y. Liu, L. Chen, Y. Zhu, X. Xiao, D. Wang, Y. Zhu, Nobiletin prevents cadmium-induced neuronal apoptosis by inhibiting reactive oxygen species and modulating JNK / ERK1 / 2 and Akt / mTOR networks in rats, Neurol. Res. 6412 (2018) 1-10. https://doi.org/10.1080/01616412.2018. 1424685. 